\title{
Kecemasan Anak Usia Sekolah Sebelum dan Sesudah Mendapatkan Informasi Saat Pemberian Obat Injeksi
}

\author{
Sutrisno ${ }^{1}$, Gipta Galih Widodo ${ }^{2}$, Herry Susanto ${ }^{3}$ \\ ${ }^{1}$ Program Studi Ilmu Keperawatan STIKes Aisyah Pringsewu Lampung, Jl.A.Yani.No. 1 A \\ Tambahrejo Kec. Gading Rejo. Kab. Pringsewu Lampung Indonesia \\ ${ }^{2,3}$ Universitas Ngudi Waluyo Ungaran \\ Email: inosutrisnochn88@gmail.com
}

\begin{abstract}
ABSTRAK
Anak yang sedang menjalani perawatan di rumah sakit seringkali mengalami masalah dalam berinteraksi dengan lingkungan sekitarnya. Kondisi bagi seorang anak menjadi suatu keadaan krisis yang terjadi karena anak berusaha untuk beradaptasi dengan lingkungan dirumah sakit, sehingga kondisi tersebut menimbulkan perasaan cemas bagi anak baik terhadap anak sendiri maupun keluarga. Tujuan penelitian ini untuk mengetahui perbedaan tingkat kecemasan anak usia sekolah sebelum dan sesudah mendapatkan informasi tentang pemberian injeksi pada kelompok kontrol dan kelompok intervensi. Metode penelitian ini menggunakan desain quasi experiment dengan sampel 17 responden kelompok kontrol dan 17 responden kelompok intervensi. Pengambilan sampel menggunakan tehnik purposive sampling. Teknik pengumpulan data menggunakan lembar observasi tentang kecemasan anak. Analisis data menggunakan uji beda 2 mean. Hasil penelitian didapatkan Terdapat perbedaan kecemasan sesudah diberikan intervensi pada kedua kelompok di RSUD Ambarawa dengan nilai p sebesar 0,010. Saran kepada petugas kesehatan setempat agar terus menerus memberikan penyuluhan dan informasi yang benar tentang pemberian obat. Sehingga dapat menurunkan kecemasan anak usia sekolah pada saat menerima tindakan pemberian injeksi.
\end{abstract}

Kata kunci: kecemasan anak, prosedur pemberian obat injeksi

\author{
ANXIETY OF CHILDHOOD SCHOOL AGE BEFORE AND AFTER GETTING \\ INFORMATION WHEN GIVING INJECTIONS
}

\begin{abstract}
Children who are undergoing hospital treatment often have problems interacting with the surrounding environment. This condition for a child becomes a state of crisis that occurs because the child is trying to adapt to the environment in the hospital, so that the condition raises anxiety for the child both against their own children and family. The purpose of this study was to determine differences in the anxiety level of school-aged children before and after obtaining information about injection administration in the control group and intervention group. This research method used quasi experiment design with sample of 17 respondent of control group and 17 respondent of intervention group. Sampling using purposive sampling technique. Data collection uses an observation sheet on child anxiety. Data analysis using difference test 2 mean. The results obtained There are differences in anxiety after being given intervention in both groups in hospitals Ambarawa with $p$ value of 0.010. Suggestions to local health officials to continuously provide counseling and correct information about drug delivery. So as to reduce the anxiety of school-age children when receiving an injection treatment.
\end{abstract}

Key words: anxiety children, injection drug administration procedures

How to Cite: Sutrisno., Widodo, G. G., Susanto, H. (2017). Kecemasan Anak Usia Sekolah Sebelum Dan Sesudah Mendapatkan Informasi Saat Pemberian Obat Injeksi. Aisyah: Jurnal Ilmu Kesehatan. 2 (2), $99-106$. 


\section{Aisyah: Jurnal Ilmu Kesehatan 2 (2) 2017, - 100}

Sutrisno, Gipta Galih Widodo, Herry Susanto

\section{PENDAHULUAN}

Dewasa ini anak-anak banyak dihadapkan dengan masalah kecemasan yang muncul akibat adanya suatu perubahan sosial yang memungkinkan mereka untuk sering berhadapan dengan orang lain dan lingkungan. Anak adalah individu yang masih tergantung pada orang dewasa dan lingkungannya, artinya membutuhkan lingkungan yang dapat memfasilitasi dan memenuhi kebutuhan dasarnya dan untuk belajar mandiri (Supartini, 2004).

Anak yang sedang menjalani perawatan di rumah sakit seringkali mengalami masalah dalam berinteraksi dengan lingkungan sekitarnya. Anak diharuskan untuk tinggal di rumah sakit, menjalani terapi dan perawatan sampai pemulangannya kembali ke rumah (Supartini, 2004). Kondisi seperti ini seorang anak dihadapkan dalam situasi krisis, yaitu mengalami sakit dan harus dirawat di rumah sakit. Keadaan krisis terjadi karena anak berusaha untuk beradaptasi dengan lingkungan dirumah sakit, sehingga kondisi tersebut seringkali menimbulkan perasaan cemas pada diri si anak sendiri maupun keluarga. Timbulnya perasaan cemas tersebut dapat memacu anak menggunakan mekanisme koping negatif maupun positif dalam mengatasi kecemasan sehingga dapat mempengaruhi perkembangan anak (Whaley \& Wong, 2003).

Seorang anak selama menjalani masa perawatannya mengharapkan ada sosok yang menjadi pengganti ibu yang dapat memberikan kasih sayang, mengerti minat dan aktivitas, sosok tersebut adalah perawat (Singgih, 1995). Pada kondisi tersebut, perawat memegang peranan penting dalam meminimalkan dampak dari perawatan anak dan membantu mengurangi kecemasan pada anak, agar anak dapat beradaptasi dengan lingkungan di rumah sakit. Tidakan perawat untuk menurunkan kecemasan tidak dapat terlepas dari hubungan terapeutik antara perawat dan pasien. Selain memberikan komunikasi terapeutik pada setiap melakukan tindakan kepada pasien, perawat juga memberikan informasi yang berhubungan dengan perawatan pasien. Pemberian informasi yang dimaksud dapat berupa informasi tentang masalah perawatan, tindakan perawatan, cara pengatasan masalah serta beberapa hal yang diperlukan pasien yang berhubungan dengan masa perawatannya.

Penelitian Haprilianti (2007) tentang hubungan antara peran perawat dalam hospitalisasi dengan kecemasan akibat hospitalisasi pada anak usia pra sekolah di Bangsal Anak RSUD Ambarawa didapatkan bahwa ada hubungan antara peran perawat dengan kecemasan akibat hospitalisasi pada anak usia pra sekolah. Hal ini menunjukkan bahwa peran perawat dapat menurunkan kecemasan yang dialami pada anak usia prasekolah.

Studi pendahuluan yang dilakukan terhadap 12 pasien anak usia sekolah di ruang kelas $1,2,3$, menunjukkan bahwa ketika perawat yang merawat mereka melakukan tindakan injeksi selalu mengajak berkomunikasi. Tetapi seringkali perawat tidak memberikan penjelasan lengkap tentang tindakan injeksi yang dilakukan misalnya penjelasan tentang jenis obat, tujuan atau kegunaannya serta menanyakan kesediaan/penolakan pasien terhadap tindakan tersebut. Dimana hal tersebut menyebabkan perasaan cemas pada pasien anak dan keluarga terhadap pelayanan perawat.

Selain wawancara langsung terhadap pasien, peneliti juga melakukan wawancara terhadap 6 orang perawat. Ke-enam perawat tersebut mengatakan bahwa mereka memang jarang sekali memberikan penjelasan secara lengkap kepada pasien tentang tindakan injeksi yang mereka lakukan kecuali jika pasien sudah terlebih dahulu menanyakan/meminta penjelasan.

Berdasarkan dari adanya fenomena yang terjadi di rumah sakit tersebut peneliti memandang perlunya pemberian informasi secara menyeluruh kepada anak dan orang 


\section{Aisyah: Jurnal Ilmu Kesehatan 2 (2) 2017, - 101 \\ Sutrisno, Gipta Galih Widodo, Herry Susanto}

tua tentang injeksi yang diberikan kepada anak untuk meminimalkan kecemasan yang dialami pada anak. Oleh karena itu peneliti ingin mengetahui lebih jauh tentang mengenai perbedaan tingkat kecemasan anak usia sekolah sebelum dan sesudah mendapatkan informasi tentang pemberian obat injeksi di RSUD Ambarawa.

Tujuan dari penelitian ini adalah untuk mengetahui perbedaan tingkat kecemasan anak usia sekolah sebelum dan sesudah mendapatkan informasi tentang pemberian injeksi di RSUD Ambarawa. Hasil penelitian ini diharapkan dapat digunakan sebagai sumber untuk mendapatkan informasi yang benar tentang manfaat pemberian informasi pada saat pemberian injeksi untuk meminimalkan kecemasan pada anak.

\section{METODE PENELITIAN}

Pada penelitian ini merupakan penelitian kuantitatif dengan menggunakan desain quasi experiment, bentuk desain penelitiannya yaitu desain pre and post test one group design. Penelitian ini dilakukan selama bulan februari 2012. Populasi dalam penelitian anak usia sekolah yang dirawat inap di RSUD Ambarawa selama 3 bulan terakhir yaitu rata-rata tiap bulan sebanyak 87 anak. Pada penelitian ini tehnik pengambilan sampel menggunakan tehnik purposive sampling. Dalam penelitian ini jumlah sampel 17 responden. Analisa univariat di lakukan terhadap tiap variabel dari hasil penelitian. Uji variabel tersebut adalah tingkat cemas. Analisa bivariat dilakukan dengan Uji wilcoxon karena data berdistribusi tidak normal. Instrumen penelitian untuk mengukur tingkat kecemasan berupa kuesioner.

\section{HASIL DAN PEMBAHASAN}

Tabel 1. Distribusi Gambaran Kecemasan Anak Usia Sekolah Sebelum dan Setelah Dilakukan Intervensi di RSUD Ambarawa

\begin{tabular}{cccccccccc}
\hline \multirow{2}{*}{ Variabel } & \multirow{2}{*}{ N } & \multicolumn{2}{c}{ Mean } & \multicolumn{2}{c}{ SD } & \multicolumn{2}{c}{ Min-Maks } & \multicolumn{2}{c}{ 95\% CI } \\
\cline { 2 - 9 } & & Pre & Post & Pre & Post & Pre & Post & Pre & Post \\
\hline \multirow{2}{*}{ Kecemasan } & 17 & 3,24 & 1,88 & 1,25 & 1,11 & $1-5$ & $0-4$ & $2,59-3,88$ & $1,31-2,45$ \\
\hline
\end{tabular}

Berdasarkan tabel 1. diketahui bahwa dari 17 responden rata-rata skor kecemasan sebelum diberikan intervensi berada pada pada angka 3,24 dengan skala kecemasan terrendah adalah 1 dan tertinggi adalah 5 . Setelah diberikan intervensi, rata-rata skor kecemasan yang diperoleh berada pada angka 1, 88 dengan skala kecemasan terrendah adalah 0 dan tertinggi adalah 4 .

Tabel 2. Perbedaan kecemasan sebelum dan sesudah diberikan intervensi.

\begin{tabular}{cccc}
\hline Kecemasan & N & Z & p value \\
\hline Sebelum* sesudah & 17 & $-3,502$ & 0,0001 \\
\hline
\end{tabular}

Berdasarkan tabel 2. didapatkan bahwa hasil analisis uji Wilcoxon terhadap 17 responden tentang perbedaan kecemasan sebelum dan sesudah diberikan intervensi di RSUD Ambarawa didapatkan nilai $p$ ( $p$ value) sebesar $0,0001(\alpha=0,05)$, sehingga dapat dirumuskan terdapat perbedaan kecemasan sebelum dan sesudah diberikan intervensi di RSUD Ambarawa.

Berdasarkan hasil penelitian bahwa dari 17 responden sebelum dilakukan intervensi, rata-rata mengalami kecemasan pada angka 3,24 dengan skala kecemasan terrendah adalah 1 dan tertinggi adalah 5. Kecemasan anak dalam menghadapi tindakan pemberian obat melalui injeksi dipengaruhi beberapa hal antara lain karena kurang pengetahuan, pemahaman, dan informasi serta adanya perubahan-perubahan yang terjadi. Adanya kegelisahan, rasa takut, 


\section{Aisyah: Jurnal Ilmu Kesehatan 2 (2) 2017 , - 102}

Sutrisno, Gipta Galih Widodo, Herry Susanto

kerisauan dan kecemasan ketika menghadapi tindakan yang diartikan sebagai sesuatu yang menyakiti, memberikan ancaman.

Cemas merupakan perasaan yang terjadi pada saat anak dirawat di rumah sakit, sesuai dengan pendapat Carson dalam Wong (2003) anak akan bereaksi terhadap stresor yang ditimbulkan oleh karena hospitalisasi baik pada saat masuk rumah sakit untuk pertama kalinya maupun selama proses hospitalisasi. Sedangkan menurut Mott (2005) lingkungan rumah sakit yang dianggap asing oleh anak akan meningkatkan kecemasan anak pada saat dirawat di rumah sakit. Menurut Stuart (2009) anak yang dirawat di rumah sakit dengan kecemasan yang tinggi memiliki kecendrungan menjadi hiperaktif dan tidak kooperatif terhadap petugas kesehatan serta menimbulkan gangguan psikologik berupa perubahan perilaku diantaranya susah makan dan gangguan tidur.

Peran yang baik yang dimiliki oleh perawat anak dalam melaksanakan pemberian obat misalnya perawat mengatur lingkungan agar anak merasa nyaman, perawat memberikan hiburan pada anak dengan mengajak anak bermain dan melihat gambar. Dalam hal ini perawat dapat memberikan lingkungan yang aman dan nyaman kepada anak agar anak tidak merasa cemas ketika sedang dirawat di rumah sakit.

Berdasarkan hasil penelitian didapatkan bahwa bahwa dari 17 responden setelah dilakukan intervensi, rata-rata mengalami kecemasan pada angka 1,88 dengan skala kecemasan terrendah adalah 0 dan tertinggi adalah 4 .

Pasien anak-anak masih mempunyai pengetahuan yang belum menyeluruh tentang proses perawatan dengan baik, tetapi dengan penjelasan yang sederhana, anak dapat mengerti dan memahami perawataan yang dilakukan adalah demi kesehatannya. Anak usia sekolah yang mempunyai pengetahuan tentang pemberian obat dengan baik, ia akan mudah memahami proses pemberian obat sebagai upaya penanganan terhadap penyakit yang memiliki manfaat tertentu untuk melawan terhadap penyakit yang sedang dihadapi, sehingga ia dapat mengantisipasi atau mengatasi kecemasan menghadapi pemberian obat.

Anak usia sekolah yang sudah pernah mendapat informasi atau pengalaman dari orang lain akan merasa lebih tenang dibanding dengan anak yang belum pernah mendapat pengetahuan sama sekali. Karena itu anak usia sekolah yang mengalami tindakan pemberian obat perlu mendapatkan pengetahuan dan informasi tentang pemberian obat guna untuk mengurangi rasa cemas baik dari buku, orang tua, kakak dan teman (Saringendyanti, 2008).

Menurut Supartini (2004) selain berperan langsung dalam meminimalkan dampak kecemasan pada anak, perawat juga mempunyai peran yang sangat penting untuk memberikan pendidikan kesehatan kepada orang tua. Hasil penelitian ini sejalan dengan penelitian Muzakki (2006) bahwa mayoritas responden yang diteliti berdasarkan tingkat kecemasan adalah dengan cemas ringan sebanyak 23 responden (76,6 \%). Muzakki (2006) menambahkan bahwa klien dengan tingkat kecemasan ringan sering ditanggulangi tanpa pemeriksaan yang serius, adapun tingkat kecemasan yang sedang dan berat akan menimbulkan dua jenis mekanisme koping antara lain reaksi yang berorentasi pada tugas (adaptif) dan mekanisme pertahanan ego (maladaptive).

Berdasarkan tabel 2, didapatkan bahwa hasil analisis uji Wilcoxon terhadap 17 responden tentang perbedaan kecemasan sebelum dan sesudah diberikan intervensi di RSUD Ambarawa didapatkan nilai $p$ sebesar $0,0001(\alpha=0,05)$, sehingga dapat disimpulkan terdapat perbedaan kecemasan sebelum dan sesudah diberikan intervensi di RSUD Ambarawa. 


\section{Aisyah: Jurnal Ilmu Kesehatan 2 (2) 2017, - 103}

Sutrisno, Gipta Galih Widodo, Herry Susanto

Menurut Freud (1998) dalam Stuart (2009) bahwa stimulus ekternal dari lingkungan seseorang melalui cerita keluarga atau teman tentang pengalaman yang menyedihkan dan trauma ketika mendapatkan tindakan injeksi. Stimulus internal dari dalam diri seseorang yaitu kurang pengetahuannya tentang pemberian obat melalui injeksi yang akan berpengaruh terhadap tingkat kecemasan seseorang. Selain itu juga menurut Keliat (2002) Klien yang menerima informasi yang benar akan meminimalkan efek samping dan lebih dapat melakukan perawatan mandiri secara optimal. Hal ini sesuai dengan hasil penelitian yang dilakukan Siswanto (2002) tentang manfaat pemberian informasi terhadap tingkat kecemasan pada pasien dengan fraktur sebelum dilakukan tindakan operasi, yang mempunyai hasil bahwa terdapat perbedaan yang signifikan antara tingkat kecemasan pada pasien yang akan dilakukan tindakan operasi antara sebelum dan setelah pemberian pendidikan kesehatan. Pendidikan kesehatan efektif untuk menurunkan tingkat kecemasan seseorang.

Hal ini sesuai juga dengan pendapat Hawari (2001) menyatakan bahwa apabila dalam setiap tindakan medis klien diberikan penjelasan tentang tindakan yang akan dilakukan, maka klien akan lebih kooperatif dan komunikatif sehingga apa yang disampaikan mudah dipahami. Hal ini dapat menurunkan tingkat kecemasan dari klien tentang akibat dari tindakan yang akan dilakukan baik pada dirinya sendiri atau pada anggota keluarga mereka.

Suatu tindakan medis yang akan dilakukan dapat menimbulkan kecemasan pada klien, hal ini dimungkinkan karena kurangnya pengetahuan tentang tindakan medis tersebut. Pemberian informasi yang jelas tentang tindakan tersebut dan risiko yang mungkin terjadi dapat mengurangi rasa kecemasan, sehingga klien dapat mengambil keputusan yang rasional terhadap tindakan yang akan dilakukan baik pada dirinya sendiri atau pada anggota keluarga mereka.

Pada penelitian ini tingkat kecemasan responden menurun setelah dilakukan pemberian informasi mengenai tindakan injeksi. Cara tersebut ternyata efektif dalam menurunkan tingkat kecemasan responden. Ada perbedaan tingkat kecemasan pada anak usia sekolah menunjukkan bahwa informasi tentang pemberian injeksi memiliki dampak positif terhadap kecemasan yang dialami oleh anak. Untuk itu perawat perlu untuk meningkatkan peranannya dalam bentuk pemberian pelayanan profesional, tidak hanya fokus pada pemenuhan kebutuhan dasar yang spesifik misalnya; oksigen, makan, minum, eliminasi, dan perlindungan tetapi juga harus diperhatikan kebutuhan lainnya misalnya; cinta dan kasih sayang, rasa aman, dan perlindungan sangat penting peranannya dalam mengurangi stres atau cemas khususnya pada anak. Selain itu perawat juga harus memperhatikan kebutuhan akan privasi bagi anak.

\section{KESIMPULAN DAN SARAN}

Berdasarkan hasil penelitian dan pembahasan, peneliti mengambil kesimpulan berupa : anak usia sekolah sebelum diberi informasi mengenai pemberian obat saat injeksi sebagian besar mengalami kecemasan ringan, sesudah diberi informasi mengenai pemberian obat saat injeksi sebagian besar tidak mengalami kecemasan, Pada penelitian ini tingkat kecemasan responden menurun setelah dilakukan pemberian informasi mengenai tindakan injeksi. Ada perbedaan tingkat kecemasan pada anak usia sekolah menunjukkan bahwa informasi tentang pemberian injeksi memiliki dampak positif terhadap kecemasan yang dialami oleh anak. Hasil penelitian ini hendaknya dapat dijadikan pertimbangan bagi perawat untuk mengantisipasi adanya kecemasan pada anak dan menjadi tambahan pengetahuan 


\section{Aisyah: Jurnal Ilmu Kesehatan 2 (2) 2017, - 104}

Sutrisno, Gipta Galih Widodo, Herry Susanto

perawat khususnya dalam hal perawatan anak usia sekolah.

Berdasarkan hasil penelitian yang telah dilakukan, saran yang dapat diberikan bagi penelitian selanjutnya perlu dilakukan penelitian terkait adanya faktor pengalaman dan trauma baik yang dialami oleh responden atau yang diasampaikan oleh lingkungan disekitar responden sehingga menyebabkan kecemasan. 


\section{Aisyah: Jurnal Ilmu Kesehatan 2 (2) 2017, - 105}

Sutrisno, Gipta Galih Widodo, Herry Susanto

\section{DAFTAR PUSTAKA}

Arikunto, S. (2002). Prosedur Penelitian; Suatu Pendekatan Praktek. Jakarta: Rhineka Cipta.

Dorlan. (2002). Kamus Kedokteran; Alih Bahasa: Huriawati Hartanto dkk. Jakarta: EGC.

Gunarso S.D. (2005). Psikologi Perawatan. Jakarta: PT.BPK Gunung Mulia.

Haprilianti, N.V. (2007). Hubungan Antara Peran Perawat dalam Hospitalisasi Dengan Kecemasan Akibat Hospitalisasi pada Anak Usia Pra Sekolah di Bangsal Anak RSUD Ambarawa. Skripsi (tidak diterbitkan).

Hawari, D. (2001). Manajemen Stress, Cemasa dan Depresi. Jakarta: Fakultas Kedokteran Universitas Indonesia.

Kaplan, B. J., and Sadock, V. A. (2010). Kaplan \& Sadock Synopsis of Psychiatry Behavioral Sciences/Clinical Psychiatry Edisi 10. Philadelphia: Lippincott Williams \& Wilkins.

Keliat, B.A. (2002). Asuhan Keperawatan pada Klien dengan Kecemasan. Jakarta: EGC.

Lewer, H. (2009). Belajar Merawat di Bangsal Anak. Alih Bahasa: Eni Noviestari, Maria A. Wijaya Rini, Editor, Ni Luh Gede Yasmin Asih. Jakarta: EGC.

Markum, A.H. (2008). Ilmu Kesehatan Anak. Jakarta: FK UI Bagian Ilmu Kesehatan Anak.

Mott, et al. (2000). Nursing Care of Children and Families. $2^{\text {nd }}$ Editor. Addison Wesiey Nursing. California: Cummings Publishing Company. Redwood City.
Muzakki. (2006). Penanggulangan Kecemasan Pasien dalam Menjalani Perawatan. Tidak diterbitkan.

Saringendyanti. (2008). Psikologi Orang Dewasa. Surabaya: Usaha Nasional.

Setiowati. (2009). Hubungan Tingkat Kecemasan Pasien Anak-anak Terhadap Peran Petugas di RS PKU Muhammadiyah Gombong dan Yogyakarta, tidak diterbitkan.

Singgih, G. D. (2005). Psikologis Praktis Anak Remaja dan Keluarga. Jakarta: PT. Gramedia Pustaka Utama.

Siswanto. (2002). Hubungan antara Pendidikan Kesehatan Terhadap Kecemasan Pasien di RSUD Grobogan, Tidak diterbitkan.

Smet, B. (2004). Psikologi Kesehatan. Jakarta: PT. Grasindo Gramedia Widiasarana Indonesia.

Sugiyono. DR. (2005). Statistik untuk penelitian. Bandung: Alfabeta.

Suliswati. (2005). Konsep Dasar Keperawatan Kesehatan Jiwa. Jakarta: EGC.

Sunarto dan Hartono, A. (2008). Perkembangan Peserta Didik. Jakarta: Rineka Cipta.

Stuart, G. W. (2009). Principle and Practice Psychiatric Nursing, 9 th ed. Philadelpia: MosBy Company.

Supartini, Y. (2004). Konsep dasar keperawatan anak. Jakarta: EGC.

Wong, D. L. (2003). Pedoman Klinis Keperawatan Pediatrik; Alih Bahasa: Monica Ester; editor bahasa Indonesia, Sari Kurnianingsih. Jakarta: EGC. 
Aisyah: Jurnal Ilmu Kesehatan 2 (2) 2017, - 106

Sutrisno, Gipta Galih Widodo, Herry Susanto 